\title{
PROPOSTA DE UM ITINERÁRIO GEOTURÍSTICO NOS CAMPOS GERAIS/PR
}

\author{
Tiago Damas Martins ${ }^{(a)}$, Bianca Carvalho Vieira ${ }^{(b)}$ \\ (a) Departamento de Ciências Geográficas (BFP/FACEPE)/Universidade Federal do Pernambuco, \\ martins.td@gmail.com \\ (b) Departamento de Geografia/Universidade de São Paulo, biancacv@usp.br
}

\section{Eixo: GEODIVERSIDADE, GEOARQUEOLOGIA E PATRIMÔNIO NATURAL}

\begin{abstract}
Resumo
Os Campos Gerais do Paraná abrigam diversos sítios de interesse Geológico/Geomorfológico, que juntamente com seu histórico processo de colonização, lhe imprimiu uma peculiaridade paisagística de interesse turístico. O presente trabalho objetivou a identificação de um itinerário a ser percorrido de bicicleta, como uma prática de cicloturismo, no município de Palmeira (PR), inventariando também os atrativos naturais e culturais associados a esta paisagem. O circuito proposto percorre $84,05 \mathrm{Km}$, atravessando sítios como as nascentes do Rio Tibagi, o Rio dos Papagaios, as Grutas do Cercado, as Estrias Glaciais e ainda, fazendas e santuários relacionados ao tropeirismo, além de colônias de imigrantes. Foram identificados também 12 pontos com a necessidade de sinalização específica.
\end{abstract}

Palavras chave: Patrimônio Natural; Palmeira; Tropeirismo; Escarpa Devoniana.

\section{Introdução}

A composição de uma paisagem natural e os processos históricos e culturais que se desenvolvem, podem se somar para tornar tal composição paisagística um atrativo para fins turísticos. Dentre as paisagens que agregam tais características, destaca-se a região dos Campos Gerais do Paraná, que abriga diversos sítios de interesse Geológico/Geomorfológico, a exemplo de Vila Velha e as Furnas, e que se associa a um particular processo de ocupação colonial, marcado pela atividade econômica do tropeirismo e a instalação de colônias agrícolas por parte de imigrantes (PIEKARZ e LICCARDO, 2007; UEPG, 2009; MARTINS e BAHL, 2012, dentre outros).

A paisagem dos Campos Gerais tida como uma zona fitogeográfica natural, com campos limpos e matas de galerias ou capões isolados de floresta ombrófila mista, com a marcante ocorrência do pinheiro Araucaria angustifolia (MAACK, 1948), se estende por $19.060 \mathrm{~km}^{2}$ na porção centro-oriental do Segundo Planalto paranaense, limitando-se a Leste pela Escarpa Devoniana e a Oeste pela escarpa da Serra Geral (MAACK, 1981). 
As formas do relevo aí encerradas são diversas, observando-se nas proximidades da cuesta erosiva da Escarpa Devoniana grandes amplitudes que se desenvolvem, "com frequentes encostas abruptas, verticalizadas, com cânions e trechos de rios encaixados" (UEPG, 2004, p. 43), sendo um destaque, por exemplo, o Cânion do Guartelá, formado pelo Rio Iapó. São típicas também as feições ruiniformes da estrutura rochosa presente no Parque Estadual de Vila Velha caracterizadas pelos intensivos processos erosivos nas rochas superficiais e os poços de desabamento conhecidos como Furnas (MARTINS et al. 2015).

A origem desta paisagem está relacionada a condições paleoambientais em que predominavam condições climáticas "muito secas e bem mais frias" (AB'SABER, 2003, p. 103) do que as atuais, e cujo a topografia é distinguida por um "desdobrar de chapadões ondulados marcados por mosaicos de campos de cimeira e pequenos bosques de araucária". Distinguem-se "alguns morros testemunhos, de rocha ligeiramente mais resistentes e fortemente fissuradas, tendo sido destacada como uma das topografias ruiniformes mais extraordinárias do país" (AB'SABER, 2003, p. 105)

O seu povoamento (por populações não indígenas) está vinculado ao tropeirismo, que se caracterizou como "um sistema social de extrema importância para a expansão e ocupação do território brasileiro nos séculos XVIII e XIX” (STRAFORINI, 2001, p. 21). O tropeirismo foi uma prática de transporte e comércio de animais, principalmente de muares, que eram criados no sul do Brasil e levados as feiras comerciais no estado de São Paulo para então suprirem a demanda de animais de carga na região das minas, no interior do país, seguindo uma rota que veio a ser denominada de "Caminho de SorocabaViamão" (STRAFORINI, 2001).

Ao longo desta rota, inúmeros núcleos de ocupação foram surgindo e, dentre eles, o atual município de Palmeira, que nas palavras de Ferreira (1999, p. 374) foi "originalmente local de pouso e curral de gado, utilizado por tropeiros [...], inicialmente denominada Freguesia Nova". Ainda se menciona a passagem, na primeira década do século XIX, das expedições militares do Tenente General João Henrique e Bohn e do Coronel Diogo Pinto de Azevedo na região do "Rincão dos Buracos, onde mais tarde se iniciou a construção da Igreja, núcleo central da Freguesia Nova de Palmeira" (FREITAS, 1991, p. 7). O município atualmente se estende por uma área de $1.470 \mathrm{~km}^{2}$ e conta com uma população de pouco mais de 32.000 habitantes (IBGE, 2010).

Assim, diante da complexidade natural e da peculiar formação histórica e cultural da região, o presente trabalho objetivou a identificação de um itinerário a ser percorrido de bicicleta, como uma prática de cicloturismo, no município de Palmeira (PR), inventariando também atrativos naturais culturais, que poderão ser integrados a um projeto de desenvolvimento geoturístico regional. 


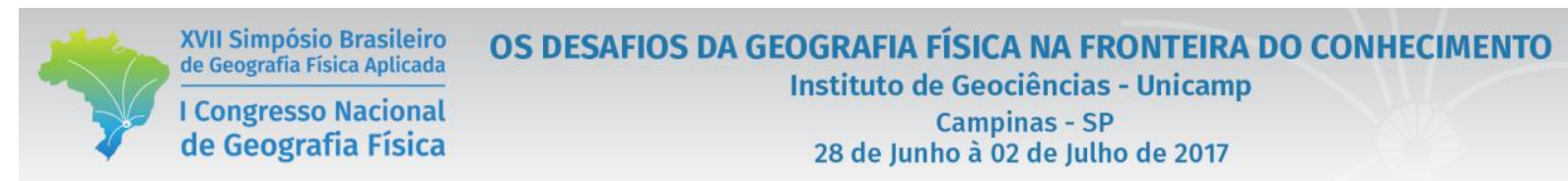

\section{Materiais e Métodos}

Para a realização deste trabalho fora selecionado o setor leste/nordeste do município de Palmeira, por abrigar sítios naturais e históricos de possível interesse turístico (Figura 1). A base cartográfica utilizada foi obtida das cartas topográficas Folha Quero-Quero (IBGE, 1990) e Folha Palmeira (DSG, 1990), ambas em escala 1:50.000. A coleta de dados para demarcação do itinerário foi efetuada com uso de um equipamento de posicionamento GPS (Global Positioning System); e ainda fora realizado documentação fotográfica dos sítios identificados.

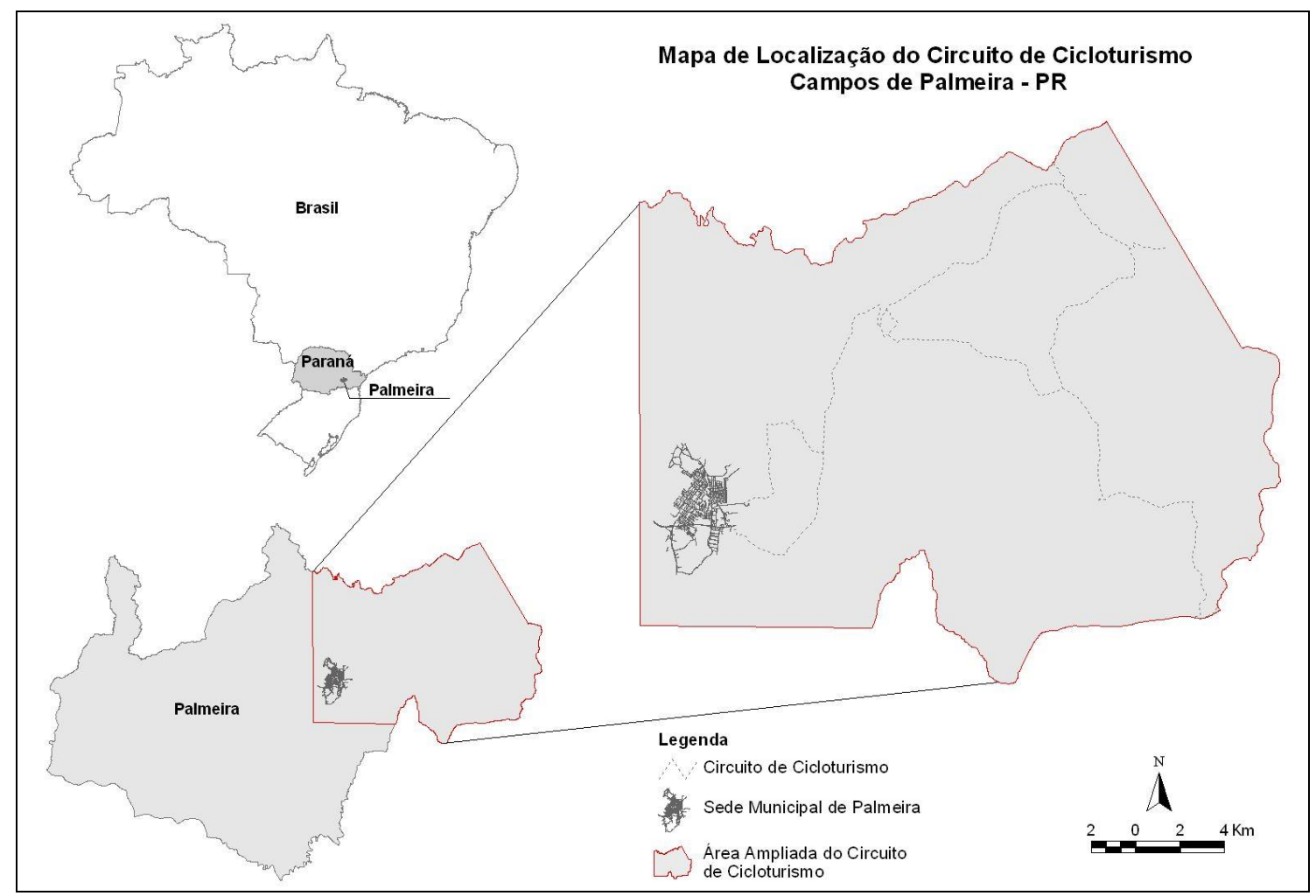

Figura 1: Localização geral da área na qual foi definido o circuito.

Os dados de GPS foram processados em um programa de SIG (Sistemas de Informação Geográfica), permitindo a elaboração dos produtos cartográficos definidos neste trabalho como Circuito de Cicloturimos Campos de Palmeira. As atividades de campo também contemplaram a definição de pontos com a necessidade de instalação de placas de sinalização, tendo como critério a ocorrência de bifurcações ao longo do itinerário do circuito em confluência com demais acessos a estradas vicinais. 


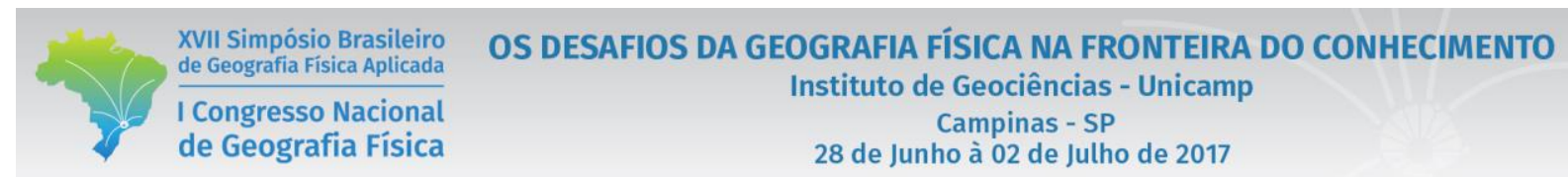

Para fins de esclarecimento, entende-se aqui que o cicloturismo é uma prática que envolve o uso da bicicleta para passeio ou viagem de lazer, com destino e duração variável, não se caracterizando como competição (SUSTAINABLE TRASPORTATION, 1999).

Quanto a definição de atrativo, verifica-se em Ignarra (2001) que se trata de uma tarefa complexa e de carácter subjetivo. Contudo, o mesmo autor destaca que quanto maior a peculiaridade individual, maior valor é agregado ao atrativo. Sendo assim, os sítios tidos como atrativos neste trabalho foram identificados pela sua peculiaridade natural e histórica, já tratados na literatura.

\section{Resultados e Discussões}

O Circuito de Cicloturismo Campos de Palmeira se estende na porção nordeste e leste do município, tendo um percurso total de 84,05 quilômetros (Figura 2). Deste montante, têm-se $50 \mathrm{Km}$ de estradas pavimentadas e $24,05 \mathrm{Km}$ de estradas não pavimentadas. Foram identificados doze pontos relacionados a bifurcações para instalação de sinalização (Figura 3).

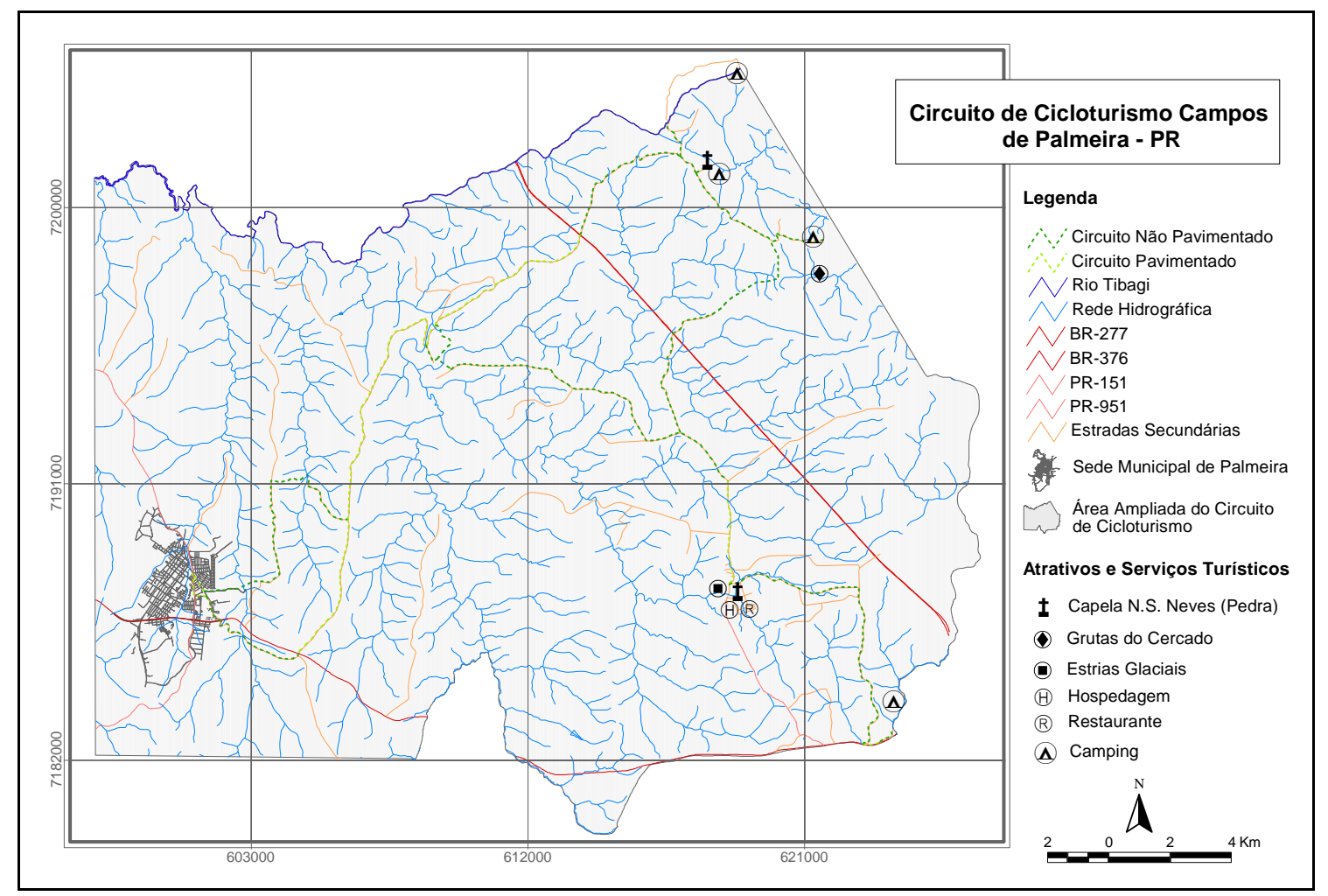

Figura 2: Mapa do Itinerário de Cicloturismo de Palmeira - PR. 


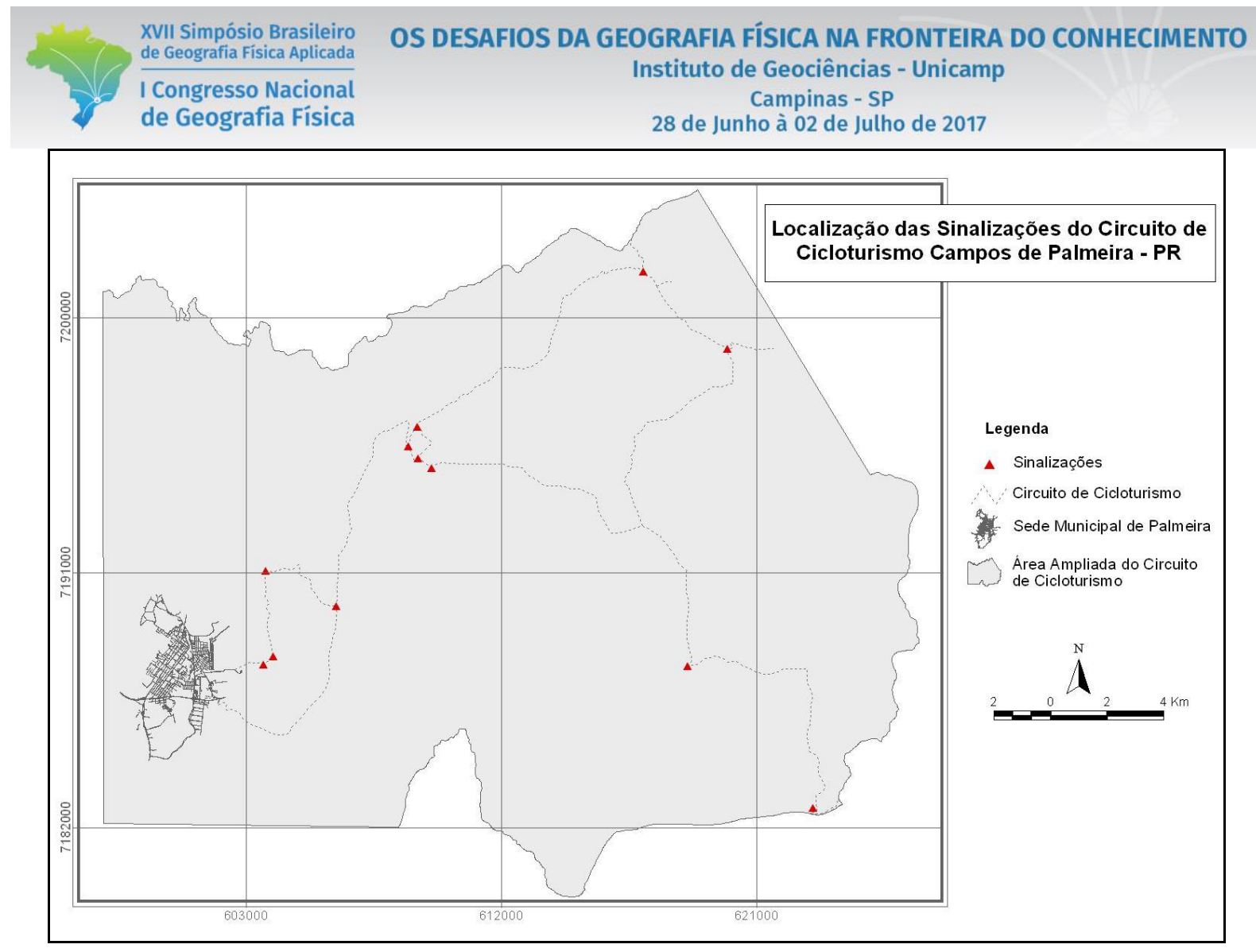

Figura 3: Pontos onde se fazem necessários a instalação de placas de sinalização para o Circuito.

A realização deste trabalho permitiu identificar atrativos, ao longo do circuito, que estão relacionados com o quadro natural e com a formação histórico-cultural da região dos Campos Gerais; descritos a seguir:

\section{Nascente do Rio Tibagi e o Rio dos Papagaios}

A localidade onde se encontra a nascente do Rio Tibagi, bem como a sua composição hidrográfica no seu alto curso foi apontada por Martins e Bahl (2010) com um potencial atrativo turístico (Figura 4A e B), tanto pelo caráter histórico de demarcação da nascente do rio, quanto pelo peculiar aspecto do relevo, marcados por cânions ocupados por mata ciliar em meio aos campos (Figura 4C).

Apontamentos históricos sobre a localização da nascente do Rio Tibagi, localmente conhecida como Serra das Almas, podem ser verificados em relatos de viajantes do século XIX, a exemplo de Bigg-Wither (1974;) e ainda, em um caráter de investigação científica, em Maack (1981).

Em Bigg-Wither (1974) o autor narra que a nascente do Rio Tibagi ocorre "no meio daquelas regiões de altas de campinas, recebendo [...] pequenos tributos de alguns ribeiros e regatos e ignorando assim o grande destino que o esperava". Já Maack (1981) revela que o "curso superior do rio Tibagi acompanha 


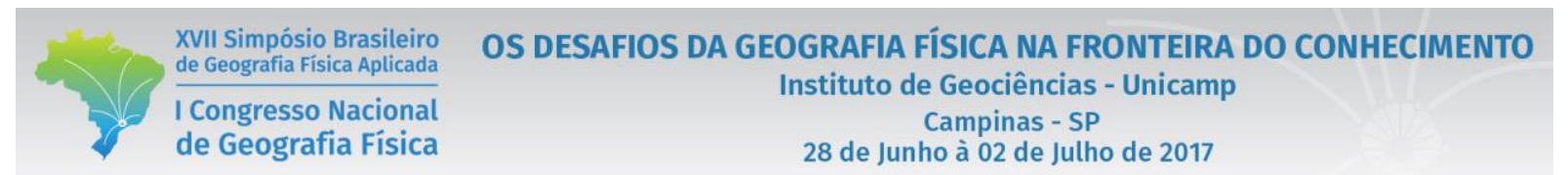

uma fenda estrutural vertical e retilínea do arenito Furnas [...] após a embocadura do arroio da Invernada" (MAACK, 1981, p. 321).

Ainda como atrativo natural tem-se o Recanto Rio dos Papagaios, que abriga uma área de lazer (Figura 4D), destacando-se também a arquitetura de uma ponte em arcos. Neste sítio natural, segundo aponta UEPG (2004), destaca-se como atrativo a configuração do relevo, determinados pela estrutura rochosa e hidrografia.

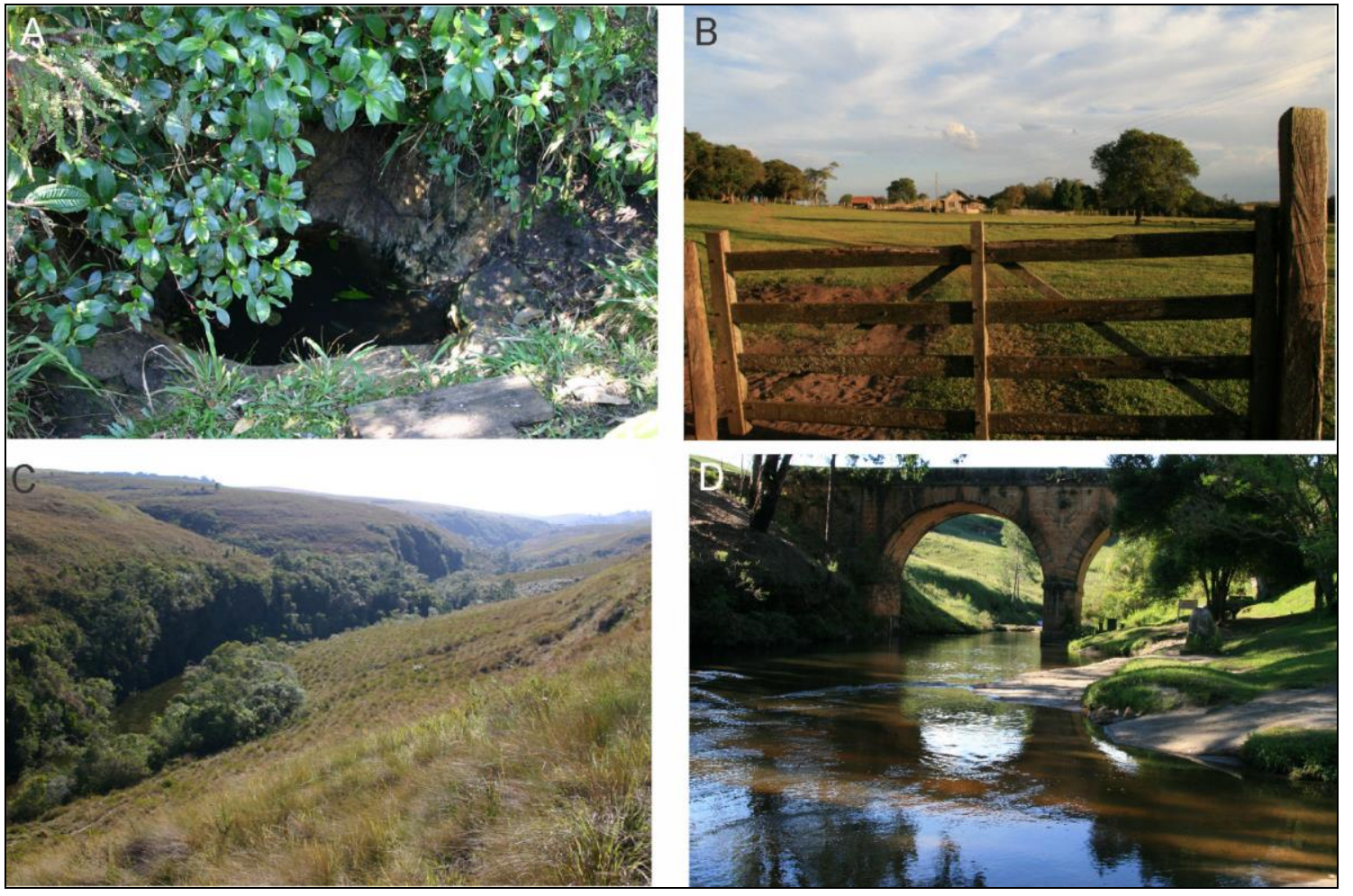

Figura 4: A) Olho d'água tido como nascente do Rio Tibagi; B) Sítio das Almas; C) Cânion formado pelo Rio Tibagi em seu curso superior; D) Ponte sobre o Rio dos Papagaios.

\section{Grutas do Cercado e Estrias Glaciais}

Como já mencionado, os Campos Gerais estão limitados a oeste pela Escarpa Devoniana, marcadamente pelos arenitos da Formação Furnas. Sotoposta a esta formação, encontram-se as rochas da série Açungui, como filitos, calcários e quartzitos (MAACK, 1981, UEPG, 2009, dentre outros). Na área adjacente ao circuito de cicloturismo, junto ao vale do Rio das Grutas (comunidade do Cercado), ocorrem formações de cavernas relacionadas à estrutura rochosa presente, em especial o calcário, destacando-se a presença de espeleotemas, como estalagmites e estalactites (Figura 5A). 
XVII Simpósio Brasileiro

de Geografia Física Aplicada

I Congresso Nacional

de Geografia Física
OS DESAFIOS DA GEOGRAFIA FÍSICA NA FRONTEIRA DO CONHECIMENTO

Instituto de Geociências - Unicamp

Campinas - SP

28 de Junho à 02 de Julho de 2017

Destaca-se também o sítio geológico conhecido como Estrias Glaciais (Figura 5B), localizado na Colônia Witimarsum, que preserva feições na superfície rochosa do Arenito Furnas (Formação Furnas) originadas durante as glaciações permo-carboníferas (BIGARELLA et al, 2003; PIEKARZ e LICCARDO, 2007; dentre outros)

Este sítio possui um painel informativo, contanto com explicações dos eventos geológicos que o originaram, implantado por um projeto turístico governamental, o que promoveu o aumento do número de visitantes, bem como a preservação do local (PIEKARZ e LICCARDO, 2007).
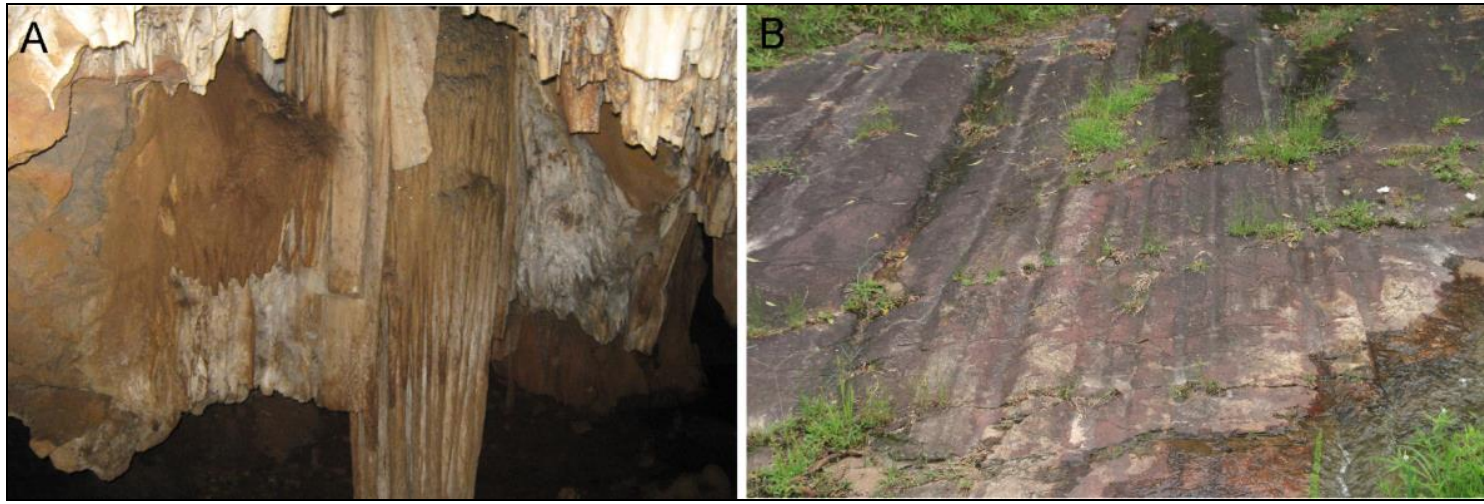

Figura 5: A) Espeleotemas no interior da Gruta do Cercado; B) Estrias glaciais no Arenito Furnas.

\section{Fazenda Santa Rita, Capela Nossa Senhora das Neves (Pedra) e Colônias Agrícolas}

Por fim, se destacam os sítios relacionados ao processo histórico de ocupação colonial, particularmente ao tropeirismo, como a Fazenda Santa Rita (Figura 6A), que preserva extensas áreas de campo e é atravessada por parte do circuito. Ainda a Capela Nossa Senhora das Neves, identificada também como Nossa Senhora das Pedras (Figura 6B), cuja a origem e edificação está relacionada às lendas populares (LOPES, 2000).

E posterior ao processo de tropeirismo, tem-se a instalação de colônias de imigrantes europeus (WAIBEL, 1949), em especial de poloneses, alemães, russos brancos e alemães-russos, cujo os elementos culturais refletem na diversidade linguística, arquitetura, na gastronomia, dentre outros (UEPG, 2004).

Dentre as colônias, a Witmarsum (Figura 6C), de origem alemã, foi fundada em 1951 por uma comunidade radicada, inicialmente, no estado de Santa Catarina e tem como base de trabalho o cooperativismo (FREITAS, 1991), desenvolvendo ainda intenso trabalho de recepção de visitantes. E assim como esta, em outros sítios ao longo do circuito, evidenciam-se a forte presença destes imigrantes e 


\section{OS DESAFIOS DA GEOGRAFIA FÍSICA NA FRONTEIRA DO CONHECIMENTO \\ Instituto de Geociências - Unicamp \\ Campinas - SP \\ 28 de Junho à 02 de Julho de 2017}

seus descendentes, a exemplo da Colônia Pugas, tanto pelo estilo arquitetônica, quanto pela conservação do idioma original (Figura 6D).
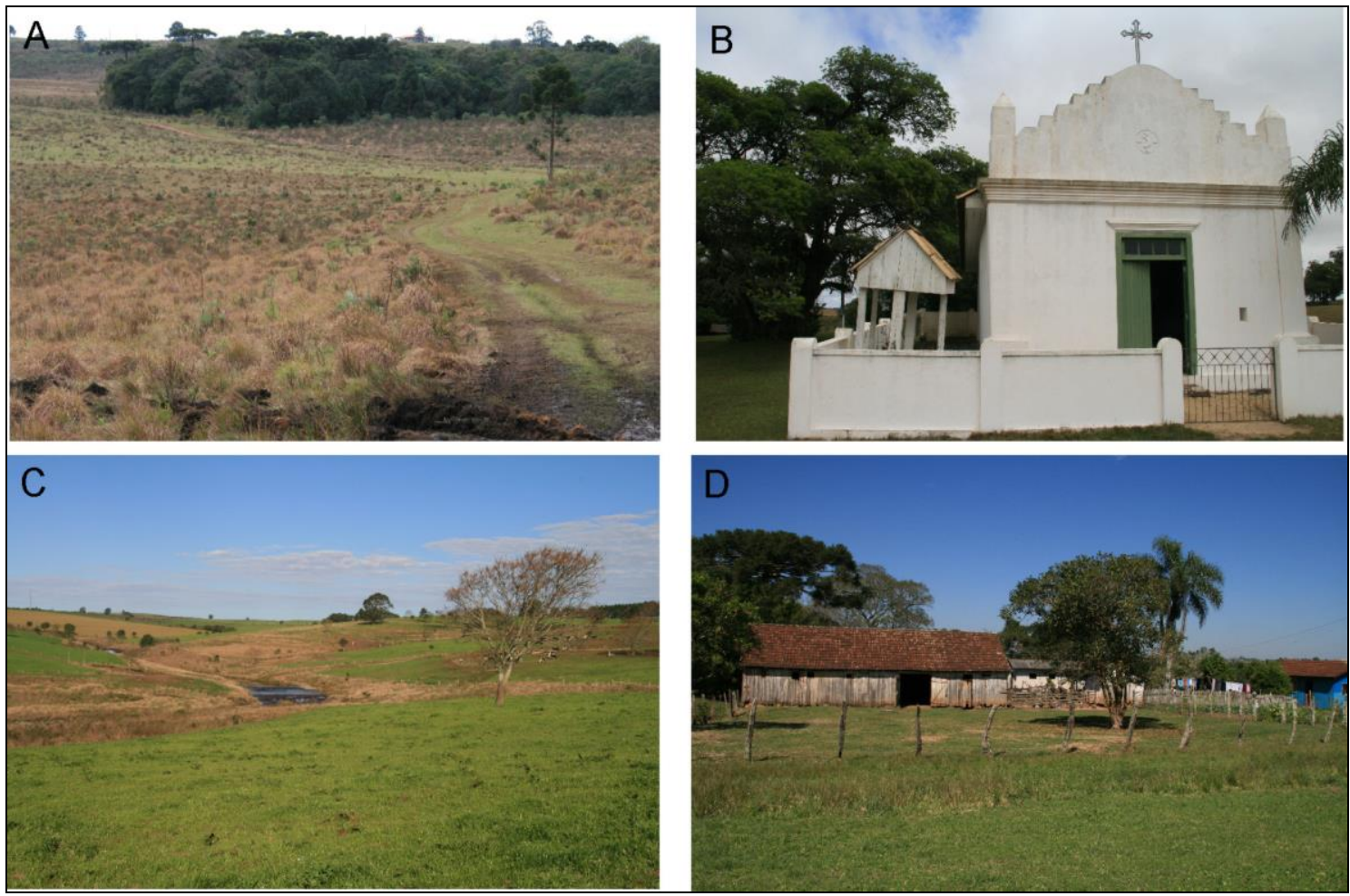

Figura 6: A) Trecho do circuito na Fazenda Santa Rita; B) Capela Nossa Senhora das Neves (Pedra); C) Aspecto dos campos na Colônia Witmarsum; D) Aspecto da ocupação rural na Colônia Pugas.

\section{Considerações Finais}

Os elementos naturais e culturais aqui destacados compõem a região dos Campos Gerais do Paraná e expressam a potencialidade dos mesmos para o desenvolvimento de atividades de turismo.

Este trabalho propõe a visitação de sítios naturais e culturais por meio de um circuito de cicloturismo, que predominantemente se estende em áreas de campos cuja a ocupação colonial é marcada, primeiramente pelo tropeirismo e, posteriormente, pela fundação de colônias agrícolas por migrantes europeus.

Trabalhos futuros poderão aprofundar os aspectos formadores de cada um dos sítios aqui identificados, no intuito de propor um sistema de orientação aos visitantes, a exemplo do que já ocorre nas estrias glaciais, além de sugerir práticas de conservação para estas áreas, diante de demandas específicas. 


\section{Agradecimentos}

Os autores agradecem a Prefeitura Municipal de Palmeira e aos revisores anônimos do SBGFA/CNGF pelos comentários e sugestões.

\section{REFERÊNCIAS}

AB`SABER, A. N. Os Domínios de Natureza no Brasil: Potencialidades Paisagísticas. São Paulo: Ateliê Editorial. 2003.

BIGARELLA, J.J.; BECKER, R.D.; SANTOS, G.F. Estrutura e Origens das Paisagens Tropicais e Subtropicais. UFSC, Florianópolis, v.3. 2003.

BIGG-WITHER, T.P. Novo caminho no Brasil meridional: a Província do Paraná. Três anos em suas florestas e campos-1872/1875. Rio de Janeiro/Curitiba: Livraria José Olímpio Editora, 1974.

DSG. DIRETORIA DE SERVIÇO GEOGÁFICO. Carta Topográfica Palmeira. 1:50.000. Folha SG. 22-X-C-II-4. MI-2840-4. $3^{\text {a }}$ ed. 1990.

FERREIRA, J. C. V. O. Paraná e seus Municípios. $3^{\text {a }}$ ed. Cuiabá: Editora Memória do Brasil. 1999.

FREITAS, A. Arremate. Palmeira: O Autor. 1991.

IBGE. Instituto Brasileiro de Geografia e Estatística. Carta Topográfica Quero-Quero. 1:50.000. Folha SG. 22-X-C-III-3. MI 2841-3. $2^{\text {a }}$ ed. 1990.

IBGE. Instituto Brasileiro de Geografia e Estatística. Cidades. Disponível em: www.ibge.gov.br. Acesso em: 01 fev. 2017.

IGNARRA, L.R. Fundamentos do Turismo. São Paulo: Pioneira Thomsom Learning, 2001.

LOPES, J.C.V. Informações sobre os bens de Nossa Senhora das Neves no Paraná. Palmeira: O autor, 2000.

LOPES, J.C.V. Raízes de Palmeira. Curitiba: O Autor. 2000.

LOPES, J.C.V. História da Fazenda Santa Rita. Curitiba: O Autor. 2005.

MAACK, R. Notas preliminares sobre o clima, solos e vegetação do Estado do Paraná. Arquivos de Biologia e Tecnologia, Vol. III, art. 12. Curitiba: UFPR, p. 99 a 200. 1948.

MAACK, R. Geografia Física do Estado do Paraná. 2 ed. Rio de Janeiro: José Olímpio. 1981.

MARTINS, T.D.; BAHL, M. A Paisagem e os Potenciais Atrativos Turísticos da Bacia Hidrográfica Do Altíssimo Rio Tibagi (Paraná/Brasil). Terra Plural, v4, n1. 2012.

MARTINS, T.D.; SILVEIRA, C.T.; CASSOL PINTO, L.M. Campos Gerais do Paraná: A regional Palympsest. In: VIEIRA, B.C.; SALGADO, A.A.; SANTOS, L.J.C. Landscapes and Landforms of Brasil, SPRINGER, 2015.

PIEKARZ, G. F., LICCARDO, A. Turismo geológico na Rota dos Tropeiros, Paraná. Revista Global Tourism, v. 3, n. 2, 2007.

SUSTAINABLE TRASPORTATION. Cycle Tourism. Information Pack TT21. 1999. Disponível em: <www.sustrans.org.uk>.

STRAFORINI, R. No caminho das tropas. Sorocaba: TCM. 2001. 
UEPG - UNIVERSIDADE ESTADUAL DE PONTA GROSSA. Patrimônio Natural dos Campos Gerais do Paraná. Ponta Grossa, 2004. Disponível em: < http://www.uepg.br/natural>.

WAIBEL, L. Princípios da Colonização Europeia no Sul do Brasil. Revista Brasileira de Geografia, Ano XI, n², p.159/217. 1949. 